\title{
Correlation of Thyroid Disorders with Abnormal Uterine Bleeding (AUB)
}

\author{
Sri Nayana Kolli¹, Manjusha Agrawal2, Yogesh Khithani³ ${ }^{3}$ Kanan Kotdawala ${ }^{4}$ \\ ${ }^{1}$ Department of Obstetrics and Gynaecology, DMIMS, Wardha, Maharashtra, India. ${ }^{2}$ Department of Obstetrics and \\ Gynaecology, DMIMS, Wardha, Maharashtra, India. ${ }^{3}$ Department of Medicine, DMIMS, Wardha, Maharashtra, India. \\ ${ }^{4}$ Department of Obstetrics and Gynaecology, DMIMS, Wardha, Maharashtra, India.
}

\section{ABSTRACT}

\section{BACKGROUND}

AUB is a common and complicated clinical entity. Thyroid disorders are the most common endocrine disorders in India with a prevalence of $26 \%$ in women and its incidence increases with age. Menstrual disturbances may accompany or may even precede thyroid disorders. We wanted to study the correlation between thyroid disorders and abnormal uterine bleeding in women of reproductive age group.

\section{METHODS}

This is cross-sectional study conducted on 165 subjects who fulfilled the eligibility criteria in the Department of OBGY, AVBRH, Sawangi for a period of 2 years. Thorough clinical examination, ultrasonography and thyroid function tests of the patients was done.

\section{RESULTS}

In this study, maximum number of patients were in the age group of 21-30 years. Regarding bleeding patterns, maximum patients had complaints of menorrhagia (46.06\%). $77.58 \%$ of patients were euthyroid, $12.12 \%$ were subclinical hypothyroid, $17.88 \%$ were overt hypothyroid and $2.42 \%$ patients were hyperthyroid. Among both subclinical and overt hypothyroid patients, the most common menstrual irregularity was menorrhagia in $55 \%$ followed by polymenorrhagia, acyclical bleeding, polymenorrhoea, oligomenorrhoea and metrorrhagia. Among hyperthyroidism, the most common menstrual irregularity was oligomenorrhoea in $75 \%$ followed by hypomenorrhoea in $25 \%$.

\section{CONCLUSIONS}

Our study concludes that the work up of any patient with AUB should essentially consist of T3 and T4 levels along with TSH levels as a mandatory part otherwise cases of subclinical hypothyroidism may be missed if only TSH levels are measured.
Corresponding Author: Dr. Manjusha Agrawal, Professor,

Department of Obstetrics and Gynaecology, DMIMS, Wardha-442001,

Maharashtra, India.

E-mail: dattamegheobgy@gmail.com

DOI: 10.14260/jemds/2020/91

Financial or Other Competing Interests: None.

How to Cite This Article:

Kolli SN, Agrawal M, Khithani Y, et al. Correlation of thyroid disorders with abnormal uterine bleeding (AUB). J. Evolution Med. Dent. Sci. 2020;9(07):398401, DOI: 10.14260/jemds/2020/91

Submission 26-11-2019,

Peer Review 21-01-2020,

Acceptance 29-01-2020,

Published 17-02-2020.

\section{KEY WORDS}

Thyroid Disorders, Abnormal Uterine Bleeding 


\section{BACKGROUND}

Abnormal uterine bleeding is a common but a complicated entity accounting for at least $20 \%$ patients attending the outpatient department. (1) Dysfunctional uterine bleeding is a commonly used term which refers to 'abnormal uterine bleeding with no demonstrable pelvic disease, pregnancy or systemic disease'. It is a diagnosis of exclusion. A broad spectrum of reproductive illnesses ranging from menstrual irregularities and abnormal sexual development to infertility and premature menopause can be seen associated with thyroid abnormalities. (2) Thyroid disorders are around ten times more common in females than males possibly due to autoimmune nature of thyroid disorders. (3)

As universally recognized, menstrual disturbances may accompany or may even precede thyroid disorders and currently, subclinical thyroid disorders are on the rising trend as compared to overt thyroid disorders. Since patients with Sub-clinical thyroid disorders do not exhibit clinically overt physical symptoms and signs, therefore go unnoticed by unwary clinicians. This most of the times leads to avoidable surgical interference and its associated complications. With modern techniques, the estimation of various hormones in blood (4) is possible in reliable and rapid manner thereby making the diagnosis of various endocrine disorders easy and medical treatment being instituted promptly. This has very gratifying results, as patient is virtually asymptomatic on adequate treatment. Hence the aim of this study is to evaluate the thyroid function in patients of reproductive age group having abnormal uterine bleeding in our area. It is comparatively cost effective than other investigations. As most of our study population is from rural background with financial constraint, unnecessary steroidal hormone treatment and surgery can be avoided by a simple investigation like thyroid levels, thereby reducing patient morbidity and their financial burden.

\section{Aim}

To study the correlation between thyroid disorders and abnormal uterine bleeding in women of reproductive age group.

\section{Objectives}

- To assess the frequency of Thyroid disorders in women with abnormal uterine bleeding.

- To assess the type of menstrual patterns in women with Hypothyroidism (Overt and Subclinical types) having Abnormal uterine bleeding.

- To assess the type of menstrual patterns in women with Hyperthyroidism having abnormal uterine bleeding.

\section{METHODS}

This is a cross-sectional study carried out in the Department of Obstetrics and Gynaecology, Acharya Vinoba Bhave rural Hospital (AVBRH) JNMC Sawangi, a tertiary care teaching hospital situated in the rural area of Wardha District, after obtaining clearance from the institutional ethics committee on Date: $04 / 9 / 2017$ with reference number: DMIMS (DU)/IEC/2017-18/6669.

\section{Sample size}

The sample size was calculated according to the following formula:

$$
\mathrm{N}=\frac{(2 \alpha / 2) 2 \cdot \mathrm{p} \cdot(1-\mathrm{p})}{\mathrm{d} 2}
$$

$=1.962 \cdot 0.71 \cdot 0.29=161.42$

0.072

$2 \alpha / 2$ - Level of significance at $5 \%$ (95\% confidence level) p - Proportion of disorders, $d$ - Desired error of margin $=7 \%$

Though the minimum calculated sample size for two years was 161, this study consists of analysis of 165 Gynaecological cases that have fulfilled all the selection criteria.

\section{Inclusion Criteria}

1. Women in reproductive age group of $18-45$ years.

2. Women with any of the following menstrual disturbances-

- Acyclical bleeding,

- Menorrhagia,

- Metrorrhagia,

- Oligomenorrhoea,

- Hypomenorrhoea

- Polymenorrhoea,

- Polymenorrhagia

3. Women with signs and symptoms of thyroid disorders-

\section{Exclusion Criteria}

1. Women with presence of pelvic pathology - Fibroids, Polyp, Cervical growth. etc.

2. Women with history of Bleeding diathesis and clotting abnormalities.

3. Women on drugs like Aspirin, Heparin, Anti-Thyroid agents, Thyroxin and other Hormonal treatment.

4. Women who were known cases of Diabetes Mellitus and Systemic Hypertension.

5. Women who were Pregnant.

6. Women with Intrauterine contraceptive device (IUCD) in situ.

7. Women who were already diagnosed cases of Thyroid disorders.

Women who did not give consent for participating in the study. A questionnaire was designed to collect information regarding demographics, menstrual complaints, history of medical illnesses and history of any drug intake. Women of reproductive age group attending the OPD and admitted in Department of Obstetrics and Gynaecology and fulfilling the inclusion criteria were taken up for this questionnaire. Informed written consent of the patients was taken in their mother tongue. Participants were interviewed in the local language. Clinical examination and Ultrasonography of all the 
patients was done. Blood samples of all the patients were sent for Serum T3, T4, TSH levels. The biochemical parameters were measured by standard laboratory technique.

\section{Statistical Analysis}

All Statistical analysis was done by using SPSS (statistical package of social science) 20.0 version. The data was presented as mean for continuous variables or absolute number (\%) for categorical variable unless otherwise specified. p-value $<0.005$ was considered statistically significant. Categorical data was compared using chi square test and independent t-test.

\section{RESULTS}

The mean age among the Euthyroid patients was $29.29 \pm 7.40$ yrs. The mean age among the Thyroid disorder patients was $32.38 \pm 7.66$ yrs. Most of the patients, $42.97 \%$ in the Euthyroid group and $45.95 \%$ in the Thyroid disorder group were from upper lower SES. Most of the Euthyroid patients (96.09\%) were from rural background while only 3.91\% were from urban population. Most of the Thyroid disorder patients $(91.89 \%)$ were from rural background while only $8.11 \%$ were from urban population. Most of the patients, $46.87 \%$ in the Euthyroid group and $43.24 \%$ in the Thyroid disorder group were Para 2. Thyroid swelling was present only in $3.13 \%$ of Euthyroid patients and in $35.14 \%$ of Thyroid disorder patients. Symptoms and signs of thyroid abnormality were present only in $30.47 \%$ of Euthyroid patients and in $54.05 \%$ of Thyroid disorder patients.

\begin{tabular}{|c|c|c|}
\hline Thyroid Status & No. of Patients (n) & Percentage (\%) \\
\hline Euthyroid & 128 & 77.58 \\
\hline Subclinical Hypothyroidism & 20 & 12.12 \\
\hline Overt Hypothyroidism & 13 & 7.88 \\
\hline Hyperthyroidism & 4 & 2.42 \\
\hline Total & 165 & 100.00 \\
\hline \multicolumn{3}{|c|}{$\begin{array}{l}\text { Table 1. Distribution of Study Subjects According to Their Thyroic } \\
\text { Status (Total Number of Patients having AUB, } n=165 \text { ) }\end{array}$} \\
\hline
\end{tabular}

\begin{tabular}{|c|c|c|c|c|c|c|c|c|}
\hline \multirow[t]{2}{*}{ 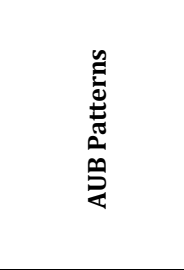 } & \multicolumn{2}{|r|}{ 苛 } & \multicolumn{2}{|c|}{ 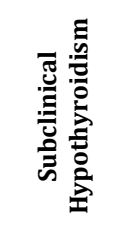 } & \multicolumn{2}{|c|}{ 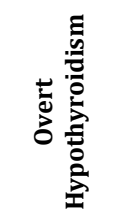 } & \multicolumn{2}{|c|}{ 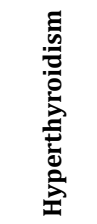 } \\
\hline & $\mathbf{n}$ & $\%$ & $\mathbf{n}$ & $\%$ & n & $\%$ & $\mathbf{n}$ & $\%$ \\
\hline Acyclical bleeding & 28 & 21.88 & 2 & 10 & 2 & 15.38 & 0 & 0 \\
\hline Hypomenorrhoea & 7 & 5.47 & 0 & 0 & 0 & 0 & 1 & 25 \\
\hline Menorrhagia & 56 & 43.75 & 11 & 55 & 9 & 69.24 & 0 & 0 \\
\hline Metrorrhagia & 6 & 4.69 & 1 & 5 & 0 & 0 & 0 & 0 \\
\hline Oligomenorrhoea & 10 & 7.81 & 1 & 5 & 1 & 7.69 & 3 & 75 \\
\hline Polymenorrhoea & 8 & 6.24 & 2 & 10 & 0 & 0 & 0 & 0 \\
\hline Polymenorrhagia & 13 & 10.16 & 3 & 15 & 1 & 7.69 & 0 & 0 \\
\hline Total & 128 & 100 & 20 & 100 & 13 & 100 & 4 & 100 \\
\hline $\begin{array}{r}\text { able 2. Dis } \\
\text { Patter }\end{array}$ & uti & of Stu & $\boldsymbol{I b}$ & & & $\begin{array}{l}o T y \\
B, n\end{array}$ & & \\
\hline
\end{tabular}

Out of the total 165 patients $(100 \%)$, most of the patients 128 (77.58\%) were Euthyroid, 20 (12.12\%) were Subclinical Hypothyroid, 13 (7.88\%) were Overt Hypothyroid and 4 (2.42\%) patients were Hyperthyroid. (Table 1). The most common type of abnormal uterine bleeding present in Euthyroid patients was Menorrhagia in $43.75 \%$ followed by
Acyclical bleeding in $21.88 \%$, Polymenorrhagia in $10.16 \%$, Oligomenorrhoea in $7.81 \%$, Polymenorrhoea in $6.24 \%$, Hypomenorrhoea in $5.47 \%$ and Metrorrhagia in $4.69 \%$. The most common type of abnormal uterine bleeding pattern present in Subclinical Hypothyroid patients was Menorrhagia in $55 \%$ followed by Polymenorrhagia in $15 \%$, Acyclical bleeding in $10 \%$, Polymenorrhoea in $10 \%$, Oligomenorrhoea in $5 \%$ and Metrorrhagia in $5 \%$. The most common type of abnormal uterine bleeding pattern present in Overt Hypothyroid patients was Menorrhagia in $69.24 \%$ followed by Acyclical bleeding in $15.38 \%$, Oligomenorrhoea in $7.69 \%$ and Polymenorrhagia in $7.69 \%$. The most common type of abnormal uterine bleeding pattern present in hyperthyroid patients was Oligomenorrhoea in $75 \%$ followed by Hypomenorrhoea in 25\%. (Table 2)

\section{DISCUSSION}

This study had been carried out in a hospital of rural setup where most of the people were from the lower side of socioeconomic status. Rural population tends to have iodine deficiency due to inadequate iodine intake which in turn might be due to less availability or less affordability of the patients as they are from lower side of socioeconomic status. Thereby they are more prone to develop Thyroid disorders. The patients with thyroid disorders have comparatively higher mean BMI than the Euthyroid population due to obesity. Menorrhagia as the most common form of AUB pattern in the total population is supported by almost all the studies- Parveen et al. (5) Verma et al. (6) and Divya et al. (7)

Both subclinical and overt hypothyroidism associated with Menorrhagia, Acyclical bleeding and Polymenorrhagia as the most common AUB patterns is supported by studies conducted by Bhavani et al. (8) and Sanghamitra et al. (9) who showed menorrhagia in $73.4 \%$ and $62.5 \%$ respectively. The cause for Menorrhagia in most of these studies is said to be due multiple factors: Defective or delay in LH response leading to Luteal phase defect and anovulation due to $\mathrm{GnRH}$ pulsatile secretion which was due to TRH induced Hyperprolactinemia, Abnormal feedback at pituitary level due to decreased SHBG production thereby leading to altered peripheral metabolism of oestrogens, Altering coagulation factors (decrease in factors VII, VIII, IX, XI) causing Menorrhagia.

Oligomenorrhoea and Hypomenorrhoea as the most common AUB patterns in Hyperthyroid patients is supported by studies conducted by Jinger et al. (10) and Somani et al. (11) who showed Oligomenorrhoea as $75 \%$ and $55.5 \%$ respectively. Studies conducted by Parveen et al. (5) Priya et al. (12) and Singh et al. (13) showed that all the patients with Hyperthyroidism have only Oligomenorrhoea as the AUB pattern. This finding in the present study shows findings significantly different from a study conducted by Bhavani et al. (8) Which showed that the most common types of AUB patterns in Hyperthyroidism were Menorrhagia in 33.33\%, Hypomenorrhoea in $33.33 \%$ and Polymenorrhoea in $33.33 \%$. The cause for this in most of these studies is said to be due multiple factors: Increased SHBG production, altered oestrogen metabolism and increased peripheral conversion of androgens to oestrogens, Elevated baseline Gonadotropin 
concentrations and increased Gonadotropin response to GnRH, Affects the haemostatic factors, including the synthesis of factor VII. Despite of all these metabolic alterations, there usually is maintenance of ovulation in Hyperthyroid women, supported by the endometrial biopsy reports according to a study conducted by Gowri et al. (14)

\section{CONCLUSIONS}

Patients with hypothyroidism both of overt and subclinical type tend to develop AUB patterns which cause excessive amounts of blood loss like menorrhagia, metrorrhagia, polymenorrhoea, polymenorrhagia and acyclical bleeding. The patients with hyperthyroidism tend to develop AUB patterns which cause lesser amounts of blood loss like oligomenorrhoea and hypomenorrhoea. Various types of menstrual disorders can be considered as possible presenting symptoms of thyroid disorders and thyroid assessment should be done in all these cases. Unless proper evaluation of thyroid function is done among these patients, we often miss an important aetiology of AUB. Thyroid function test is a low cost, readily available test and can detect a potentially curable cause of AUB which would help in forming proper treatment plan for these patients. Thus, the work up of any patient with AUB should essentially consist of T3 and T4 levels along with TSH levels as a mandatory part, otherwise cases of subclinical hypothyroidism ought to be missed if only TSH levels are measured. Simple treatment with thyroxin in cases of hypothyroidism and with anti-thyroid drugs in cases of hyperthyroidism can avoid unnecessary surgical procedures, thereby reducing patient morbidity and in turn their financial burden.

\section{REFERENCES}

[1] Nesse RE. Abnormal vaginal bleeding in perimenopausal women. Am Fam Physician 1989; 40 (1):185-92.

[2] Thomas R, Reid RL. Thyroid disease and reproductive dysfunction: a review. Obstet Gynecol 1987;70 (5):78998.
[3] Mazzaferri EL. Evaluation and management of common thyroid disorders in women. Am J Obstet Gynecol 1997;176 (3):507-14.

[4] Akande EO, Hockaday TD. Plasma luteinizing hormone levels in women with thyrotoxicosis. J Endocrinol 1972;53 (1):173-4.

[5] Parveen M, Kumari S, Haque SS, et al. Evaluation of thyroid profile status in women with abnormal uterine bleeding in north Indian population. Int J Biomed \& Adv Res 2017;8 (7):288-91.

[6] Verma SK, Pal A, Jaswal S. A study of thyroid dysfunction in dysfunctional uterine bleeding. Int J Reprod, Contracept Obstet and Gynec 2017;6 (5):2035-9.

[7] Maria JD, Jayakumari S, Sundaram PS. A prospective study on hypothyroidism in premenopausal women. Int J Pharm Sci Rev Res 2016;39 (1):183-7.

[8] Bhavani N, Sathineedi A, Giri A, et al. A study of correlation between abnormal uterine bleeding and thyroid dysfunction. Journal of Recent Trends in Science and Technology 2015;14 (1):131-5.

[9] Mohapatra S, Behera SK. Prevalence of hypothyroidism in patients with provisional diagnosis of dub. MedPulse International Journal of Gynaecology 2017;3 (1):23-9.

[10] Jinger SK, Verma A, Dayma I, et al. To study the thyroid profile in menstrual disorder at tertiary care hospital in northern western Rajasthan, India. International Journal of Research in Medical Sciences 2017;5 (5):2212-14.

[11] Somani SR, Somani SG. Study of thyroid dysfunction in premenopausal women with abnormal uterine bleeding. Int J Sci \& Res 2015;4 (7):487-9.

[12] Paari P, Sindhuja TP, Dhinakaran S. Prevalence and patterns of thyroid dysfunction in women with abnormal uterine bleeding in urban Southern India. Paripex Indian Journal of Research 2017;6 (7):19-20.

[13] Singh S, Sahoo S, Das PC. A study of thyroid dysfunction in dysfunctional uterine bleeding. International Journal of Reproduction, Contraception, Obstetrics and Gynecology 2018;7 (3):1002.

[14] Gowri M, Radhika BH, Ramaiaha R. Role of thyroid function tests in women with abnormal uterine bleeding. International Journal of Reproduction, Contraception, Obstetrics and Gynecology 2014;3 (1):54-7. 